\title{
Submerged Aquatic Vegetation Patch Size Affects Fish Communities in a Turbid-Algal Lake
}

OPEN ACCESS

Edited by:

Rob Hale,

The University of Melbourne, Australia

Reviewed by:

Jinlei Yu,

Nanjing Institute of Geography and

Limnology (CAS), China

Melissa Holbrook Schmitt,

University of California, Santa Barbara,

United States

${ }^{*}$ Correspondence:

Audrey Looby

alooby@ufl.edu

Specialty section:

This article was submitted to

Animal Conservation,

a section of the journal

Frontiers in Conservation Science

Received: 23 January 2021 Accepted: 07 April 2021 Published: 29 April 2021

Citation:

Looby A, Reynolds LK, Adams CR and Martin CW (2021) Submerged

Aquatic Vegetation Patch Size Affects

Fish Communities in a Turbid-Algal

Lake. Front. Conserv. Sci. 2:657691.

doi: 10.3389/fcosc.2021.657691

\begin{abstract}
Audrey Looby ${ }^{1,2 *}$, Laura K. Reynolds ${ }^{3}$, Carrie Reinhardt Adams ${ }^{4}$ and Charles W. Martin ${ }^{1}$
${ }^{1}$ Nature Coast Biological Station, Institute of Food and Agricultural Sciences, University of Florida, Cedar Key, FL, United States, ${ }^{2}$ Fisheries and Aquatic Sciences, Institute of Food and Agricultural Sciences, University of Florida, Gainesville, FL, United States, ${ }^{3}$ Soil and Water Sciences, Institute of Food and Agricultural Sciences, University of Florida, Gainesville, FL, United States, ${ }^{4}$ Environmental Horticulture, Institute of Food and Agricultural Sciences, University of Florida, Gainesville, FL, United States
\end{abstract}

Submerged aquatic vegetation (SAV) is declining worldwide, leading to subsequent reductions in the ecological functions associated with SAV in shallow aquatic ecosystems, including providing habitat for fishes. Extensive restoration efforts are required to reverse this trend, but studies focusing on aquatic vegetation have been uncommon in recent years relative to other primary producers. Evaluations of the most beneficial SAV species and characteristics for fishes are especially rare. Because of the potentially complex and inconsistent responses of fish to different management actions, further research is necessary to evaluate the species-specific and community-level effects of SAV to inform restoration decision-making. To examine what SAV characteristics increase fish habitat use in a turbid-algal lake undergoing restoration, we sampled 29 areas around Lake Apopka, Florida (USA) with fyke nets and trotlines. We examined the impact of eight environmental variables on fish abundance, biomass, community structure, and predation potential. For each approximated $0.6 \mathrm{~m}^{2}$ increase in SAV patch size, total fish biomass catch increased $6.5 \mathrm{~g} \mathrm{hr}^{-1}$. Fish community composition based on abundance also changed with an increase in SAV patch size. The number of bait items missing from trotlines, a measure of predation potential, was most affected by water temperature, wind speed, and time of day, but not by the SAV variables tested. These results expand existing knowledge of fish habitat use of SAV and will inform future management efforts to conserve and restore fish communities by focusing on specific SAV characteristics such as patch size.

Keywords: restoration, plant-animal interactions, habitat, macrophytes, Vallisneria, Potamogeton, Hydrilla

\section{INTRODUCTION}

Submerged aquatic vegetation (SAV) plays a critical role in the ecological functions of shallow lake ecosystems, including reducing sediment resuspension, increasing water clarity and quality, and providing important habitat for fauna including fishes (Carpenter and Lodge, 1986; Martin and Valentine, 2012; Short et al., 2016). Intermediate coverage (10-40\%) of vegetation may promote high species richness, growth, foraging, and survival of fishes, notably juveniles and smaller individuals, due to optimal spaces for predator-prey interactions and edge effects (Killgore et al., 1993; Lauridsen and Buenk, 1996; Thorp et al., 1997; Richardson et al., 1998). Furthermore, at least nineteen freshwater fish families, such as Centrarchidae and Cyprinidae, occupy or rely on 
vegetation for ideal refuge, food resources, reproduction, and nursery habitat (Dibble et al., 1997). Despite its value in freshwater ecosystems, global aquatic vegetation is declining at an accelerating rate, especially for SAV and in lakes that are $>50$ $\mathrm{km}^{2}$ (Zhang et al., 2017).

Planting SAV as part of lake restoration efforts has the potential to increase desirable fish communities in lakes. Fish communities may react differently, however, depending on a variety of factors. These factors include the architectural differences among plant species (Dibble et al., 1996; Martin and Valentine, 2011), whether a water body is in a turbid or clearwater state (Van Onsem et al., 2010), if vegetation is restored or natural (Slagle and Allen, 2018), or the amount of light diffusion through SAV (Harrel and Dibble, 2001). Effectively increasing vegetation coverage can require extensive restoration efforts (Zhang et al., 2017). Additionally, management actions may have counterintuitive results on fish communities, such as a sudden decline in recruitment after habitat improvement (Pine et al., 2009), further complicating restoration efforts. Such varying responses can result in confounding conclusions that are difficult to translate into management recommendations (Pine et al., 2009), requiring further research to ascertain what defines optimal SAV for fish habitat use.

In order to inform future SAV restoration and conservation efforts, we examined differences in fish abundance, biomass, community composition, and predation potential among SAV habitats and how other variables, such as time of day and water temperature, affect fish habitat use. To accomplish this, we sampled the fishes in bare substrate and SAV meadows of different sizes and species assemblages in Lake Apopka, Florida (USA) - a site of ongoing, extensive lake restoration efforts. We hypothesized phytophilic fishes, such as Centrarchids, would increase with SAV coverage while pelagic, schooling fishes, such as Dorosoma spp., would decrease.

\section{METHODS}

\section{Study Site}

Lake Apopka is located northwest of Orlando, in Lake and

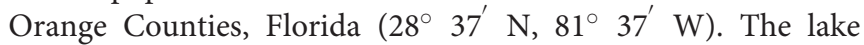
is relatively large $\left(\sim 124 \mathrm{~km}^{2}\right)$ and shallow (mean depth 1.7 m); (Bachmann et al., 1999). Until 1947, Lake Apopka was characterized by mostly clear water and dense macrophyte coverage of 70\% (Clugston, 1963). Beginning in the 1920's, Lake Apopka experienced a number of anthropogenic and natural disturbances that subsequently caused a shift from a macrophytedominated state to a turbid-algal state that persists to this day (US Environmental Agency, 1978; Bachmann et al., 1999, 2001). Populations of the less desirable gizzard shad (Dorosoma cepedianum) began increasing in Lake Apopka (Clugston, 1963), while the largemouth bass (Micropterus salmoides) population, which had supported a popular fishery, began declining and remains lower than expected compared to other nearby lake systems (Bachmann et al., 1996; Murphy, 2005). The loss of largemouth bass is suspected to be related to the loss of macrophytes (Bachmann et al., 1999) as opposed to the change in trophic state (Bachmann et al., 1996). Recently, large-scale plantings of SAV have been underway at Lake Apopka, making it an ideal location to examine how fish utilize SAV in a turbidalgal lake. The SAV planting efforts have focused on Vallisneria americana and Potamogeton illinoensis, as both were historically present in Lake Apopka before its switch to a turbid-algal state (Bachmann et al., 2001). Hydrilla verticillata, an invasive SAV species, has also recently expanded in the lake (Murphy, 2005).

\section{Field Sampling}

We sampled fish abundance, biomass, community composition, and predation potential in addition to environmental variables at a total of eight sites around the north and east shores of Lake Apopka (Supplementary Figure 1) from mid-June to midAugust 2019. Sites were selected based on their inclusion in an ongoing restoration effort in Lake Apopka to both inform the goals of the restoration as well as to more broadly study the impacts of SAV on fish communities. Only restoration sites that had at least one SAV habitat and one bare habitat were sampled; therefore only eight sites and 29 habitats were sampled. Three habitats-one bare habitat and two SAV habitats-were sampled at five of the sites. At both sites AP9 and AP20, where many SAV patches were present, two sets of three habitats were sampled. At AP21, where fewer patches were present, only one bare habitat and one SAV habitat were sampled. Each habitat within a site was sampled once. Habitats included $V$. americana, $P$. illinoensis, a mix of the two, or bare ( $V$. americana and $P$. illinoensis not present). Each SAV habitat was at least 1.5 by $1.5 \mathrm{~m}$. Any P. illinoensis was planted as part of Lake Apopka restoration projects in the past 5 years. The $V$. americana may have been naturally occurring, planted within the past 5 years, or planted over 5 years ago as part of historical restoration effortsvegetative spread and/or unclear success from recent or historical plantings make identifying the source difficult. Sites were at least $100 \mathrm{~m}$ apart and each habitat sampled was at least $10 \mathrm{~m}$ from another sampled habitat or unsampled SAV meadow.

We also took environmental data at each site or habitat. At each site, we measured salinity (ppt), depth (m), dissolved oxygen (mg L $\mathrm{m}^{-1}$ and $\%$ saturation), temperature $\left({ }^{\circ} \mathrm{C}\right)$, continuous wind speed $\left(\mathrm{m} \mathrm{s}^{-1}\right)$ and direction, and secchi depth $(\mathrm{m})$ in open water in the approximated center of the site and within $50 \mathrm{~m}$ of the habitats sampled. Water quality measurements were taken with a YSI ProDSS and associated probes held just below the water surface. Continuous wind speed was measured with a Proster TL017 handheld anemometer, and wind direction was measured with a handheld compass. For each habitat within a site, we estimated the patch size based on an index of $0-$ 5 with 0 being a bare habitat and each increase of 0.5 in the index being equivalent to an approximated increase in patch size of 0.75 by $0.75 \mathrm{~m}$ (Supplementary Figure 2). We did not measure shoot counts because of poor water visibility and high numbers of plants. We estimated the distance of the center of the habitat from shore and we recorded the presence/absence of $H$. verticillata (Supplementary Table 1). Other SAV (e.g., Ceratophyllum demersum, Najas guadalupensis) were occasionally observed in low abundances in bare habitats, but $H$. verticillata was the only species with comparable abundance to $V$. americana and $P$. illinoensis, so it was the only 
species accounted for as a separate variable. Across sampling days, the weather was relatively similar, with clear skies or partly cloudy at the beginning of sampling in the morning and afternoon storms beginning shortly after ending sampling.

We sampled fishes at each habitat on consecutive days using two techniques, fyke nets and trotlines. These methods were chosen because they are passive approaches minimally destructive to SAV; they were meant to target different fish sizes, species, and trophic levels; and they have been shown to be effective in freshwater fish sampling (Diana et al., 2006; Hubert et al., 2012; Bonvechio et al., 2014). Each fyke net was made up of two rectangular conduit $0.9 \times 1.2 \mathrm{~m}$ frames, five $63.5 \mathrm{~cm}$ galvanized hoops, two throats, a $15.24 \mathrm{~m}$ long lead, and $0.6 \mathrm{~cm}$ mesh size with a black net coat treatment. Each trotline had 24 hooks (sizes alternating between 5/0,3/0, 4/0, and 2/0) with each hook baited with half of a nightcrawler worm $(4-7 \mathrm{~cm})$, purchased from the same supplier. The bait and hook sizes were chosen based on expert advice and published diet contents to cover a broad range of target species (most notably, Centrarchids and Ictalurids); (Froese and Pauly, 2019). Both gear types were deployed perpendicular to shore for $2-3 \mathrm{~h}$, since pilot tests and catch accumulation curves indicated catch-per-unit effort was maximized over this interval (Supplementary Figure 3). We also tested trotlines overnight for $\sim 12$ hours at two sites in all habitat types $(n=6)$, but only one fish was caught among the trotlines, thus the overnight deployment was not repeated. Both gear types were deployed starting at the shore if the habitat distance from shore was $0-3 \mathrm{~m}$. Otherwise, the gear types were deployed at the shoreward edge of the habitat. In the case of the SAV habitat types, fyke nets and trotlines were deployed through the middle of the SAV patch, with SAV on both sides of the gear. Due to the small size of many of the SAV patches sampled, the entire fyke net wall or all the trotline hooks were not necessarily within the SAV patch. We considered this minimal extension $(<7 \mathrm{~m})$ beyond the edge of the patch to be fishing edges of the habitat and thus fish catch attributable to the patch itself. All captured fishes were identified to species, measured ( $\mathrm{mm})$, weighed $(\mathrm{g})$, and returned to the lake. We also recorded the number of worms missing from hooks on the trotlines as a measure of predation potential similar to a tethering experiment (Puntila et al., 2012).

We validated that our chosen sampling methods and protocols were effective at sampling fish communities with comparison testing at Lake Apopka and nearby Little Lake Conway. Little Lake Conway was chosen because of its proximity to Lake Apopka $(40.2 \mathrm{~km})$ and because it is a less degraded lake consisting of extensive macrophytes, visibility to the bottom $(>3 \mathrm{~m})$, sandy substrate, and near $100 \%$ SAV coverage throughout. In mid-September, we sampled using fyke nets and trotlines at two SAV habitats at Lake Apopka and two SAV habitats at Little Lake Conway. Sampling was successful, with Little Lake Conway having higher catch and more worms missing than Lake Apopka (Table 1), thus demonstrating the efficacy of our sampling methods.

\section{Data Analysis}

We conducted statistical analyses to assess which habitat and environmental variables had a statistically significant $(p<$
$0.05)$ or marginally significant ( $p=0.05-0.10)$ effect on fish abundance, biomass, community composition, and predation potential per unit effort (fyke net or trotline soak time expressed in hours). For the fyke net data, analyses of fish community composition using both the abundances of each species caught (hereafter, fish community abundance) and the biomasses of each species caught (hereafter, fish community biomass) were made using a multivariate approach, while analyses of total fish abundance and biomass, diversity indices, and individual species abundances used a univariate approach. The number of worms eaten at the end of trotline soak times were also analyzed with a univariate approach. We conducted all statistical analyses in $\mathrm{R}$ ( $\mathrm{R}$ Core Team, 2019) version 3.5.1 (2018-07-02) with packages “vegan" (Oksanen et al., 2019), "reshape" (Wickham, 2007) and "ggplot2" (Wickham, 2016).

The environmental data (i.e., both habitat and site characteristics and measurements) used in analyses consisted of eight variables: sampling time of day, continuous wind speed $\left(\mathrm{m} \mathrm{s}^{-1}\right)$, the estimated size of SAV patch sampled (index of $0-5$, as described above), the estimated distance of the center of each habitat sampled to the shoreline $(\mathrm{m})$, the habitat type $(P$. illinoensis $n=8, V$. americana $n=8$, mix $n=3$, or bare $n=$ $10)$, the presence $(n=11)$ or absence $(n=18)$ of $H$. verticillata, water temperature $\left({ }^{\circ} \mathrm{C}\right)$, and water depth $(\mathrm{m})$. Salinity $(\mathrm{ppt})$ and secchi depth $(\mathrm{m})$ were consistent across all sites (0.16$0.18 \mathrm{ppt}$ and $0.30-0.55 \mathrm{~m}$ respectively) and dissolved oxygen (mg L ${ }^{-1}$ ) was highly dependent on time of day, so they were excluded from the analysis (Supplementary Table 2). The noncategorical environmental data were log-transformed, and all of the environmental data were scaled. Fyke net fish community abundance and biomass data were Hellinger-transformed (Legendre and Gallagher, 2001). Two samples had zero fish caught and so were excluded from the fish community analyses.

A detrended correspondence analysis of the fyke net fish community data demonstrated that a canonical correspondence analysis (CCA) was the appropriate constrained ordination analysis for the data. We ran the CCA on all 12 species and all eight variables. To reduce the number of environmental variables to that appropriate for a CCA, we conducted forward selection with a relaxed $\alpha$ of 0.1 to capture marginally statistically significant results. For the fish community abundance data, the only variable selected was patch size. The result was the same when habitat type was excluded as a variable because of the multicollinearity with patch size ( $>0.7$ correlation value). When patch size was excluded, habitat type was selected. Because patch size was selected when both habitat type and patch size were included, the patch size variable is the focus of our results.

We calculated the Shannon and Simpson diversity indices of the fyke net catches. We used linear regression to evaluate how the Shannon diversity index, Simpson diversity index, and individual species abundances from the fyke net catches changed with SAV patch size to further describe the change in fish community abundance. We also examined the most abundant species in the fyke nets, threadfin shad (Dorosoma petenense), by running a Similarity Percentage (SIMPER) analysis of their contribution to Hellinger-transformed community structure in the Bray Curtis dissimilarity index. We used multiple linear 
TABLE 1 | Results of method validation testing in Lake Apopka and a macrophyte-dominated lake, Little Lake Conway.

\begin{tabular}{|c|c|c|c|c|c|}
\hline Sampling method & Lake sampled & Habitat type & SAV patch size & Sampling results & Sampling results per hour \\
\hline \multirow[t]{4}{*}{ Fyke nets } & Little Lake Conway & $\operatorname{mix}$ & 5 & 8 bluegill, 3 fliers & 5.28 fishes \\
\hline & & P. illinoensis & 5 & 4 bluegill, 5 fliers & 5.29 fishes \\
\hline & Lake Apopka & $\operatorname{mix}$ & 4.5 & 3 threadfin shad, 1 coastal shiner & 2.05 fishes \\
\hline & & P. illinoensis & 4.5 & 0 catch & 0 fishes \\
\hline \multirow[t]{4}{*}{ Trotlines } & Little Lake Conway & $\operatorname{mix}$ & 5 & 12 worms missing, 0 catch & 5.53 worms \\
\hline & & P. illinoensis & 5 & 11 worms missing, 0 catch & 5.08 worms \\
\hline & Lake Apopka & P. illinoensis & 4.5 & 0 worms missing, 0 catch & 0 worms \\
\hline & & P. illinoensis & 2 & 2 worms missing, 0 catch & 1.14 worms \\
\hline
\end{tabular}

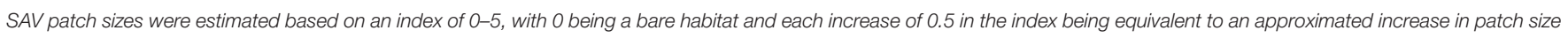
of 0.75 by $0.75 \mathrm{~m}$.

regression with forward selection $(\alpha=0.05)$ to evaluate how total biomass per soak time hour, total abundance per soak time hour, and the worms missing from trotlines per soak time hour changed with the same transformed and scaled environmental variables as the fish community data analysis. A more comprehensive description of the data analyses, including which $\mathrm{R}$ functions were used for each test, is included in the Supplementary Material.

\section{RESULTS}

Fyke net total fish biomass increased $6.5 \mathrm{~g} \mathrm{hr}^{-1}$ per approximated $0.6 \mathrm{~m}^{2}$ increase in SAV patch size (Figure 1; linear regression: adjusted R-squared $=0.1998, F_{1,27}=7.991, p=0.009$, residual standard error: 24.98 , from $\mathrm{lm}$ function). SAV patch size also contributed to marginally significant differences in the fyke net fish community abundance (CCA: adjusted R-squared $=0.02$, $F_{1}=1.5593, p=0.08$ ). No other environmental variables contributed significantly to the variation in fish community abundance or total fish biomass. None of the environmental variables included in the analysis contributed significantly to the variation in fish community biomass or total fish abundance.

Differences in abundance with SAV patch size varied by fish species (Figures 2A,B). A total of 12 species were caught in the fyke nets: threadfin shad, warmouth (Lepomis gulosus), bluegill (Lepomis macrochirus), brown bullhead (Ameiurus nebulosus), gizzard shad, Seminole killifish (Fundulus seminolis), golden silverside (Labidesthes vanhyningi), dollar sunfish (Lepomis marginatus), redear sunfish (Lepomis microlophus), spotted sunfish (Lepomis punctatus), coastal shiner (Notropis petersoni), and black crappie (Pomoxis nigromaculatus). The abundance of threadfin shad decreased $46 \%( \pm 61 \%)$ from bare to large SAV patch size. Furthermore, SIMPER analysis of their contribution to community structure in the Bray-Curtis dissimilarity index indicated high contribution (97\%) to the community dissimilarity between SAV patch size 0 and 1 , but only $25 \%$ between size 4.5 and 5 . The other fish species caught in more than one fyke net showed some increase in abundance with an increase in SAV patch size, though the rate of increase was relatively small and varied among species (Supplementary Table 3). Warmouth was the only species whose

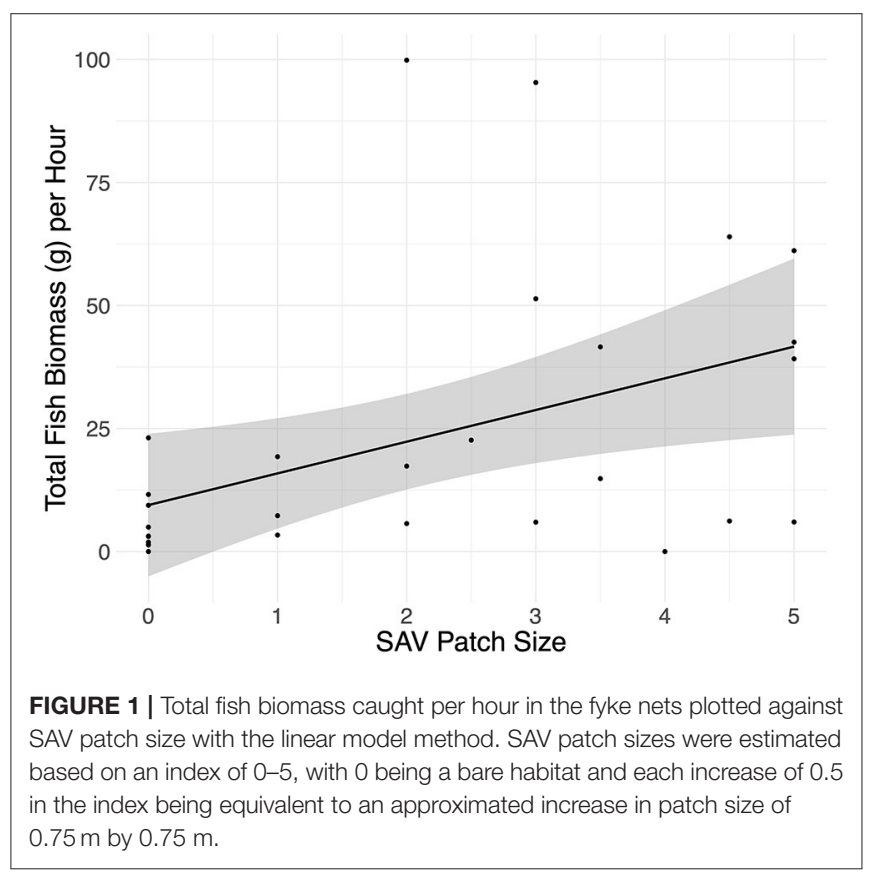

abundance showed a statistically significant relationship with SAV patch size (linear regression: adjusted R-squared $=0.107$, $F_{1,27}=4.356, p=0.04645$, residual standard error: 0.3123 , from $\mathrm{lm}$ function). The Shannon diversity index of the fish communities showed some increase with SAV patch size, though not significantly (Figure 2C; linear regression: adjusted Rsquared $=0.025, F_{1,27}=1.719, p=0.2008$, residual standard error: 0.4008 , from $\mathrm{lm}$ function) and the Simpson diversity index showed little to no increase (Figure 2D; linear regression: adjusted R-squared $=-0.006013, F_{1,27}=4.356, p=0.3696$, residual standard error: 0.8326 , from $\mathrm{lm}$ function). All of the species that were only caught in a single fyke net were found in SAV patch sizes 2.5 or larger (Supplementary Table 4). Although individual trends were almost entirely not significant, the cumulative response to SAV patch size drives the marginally significant changes detected in fish community abundance.

A total of six fish were caught on all 29 2-h trotlines that were deployed. The species caught were two brown bullhead, one yellow bullhead (Ameiurus natalis), one redear sunfish, and two 


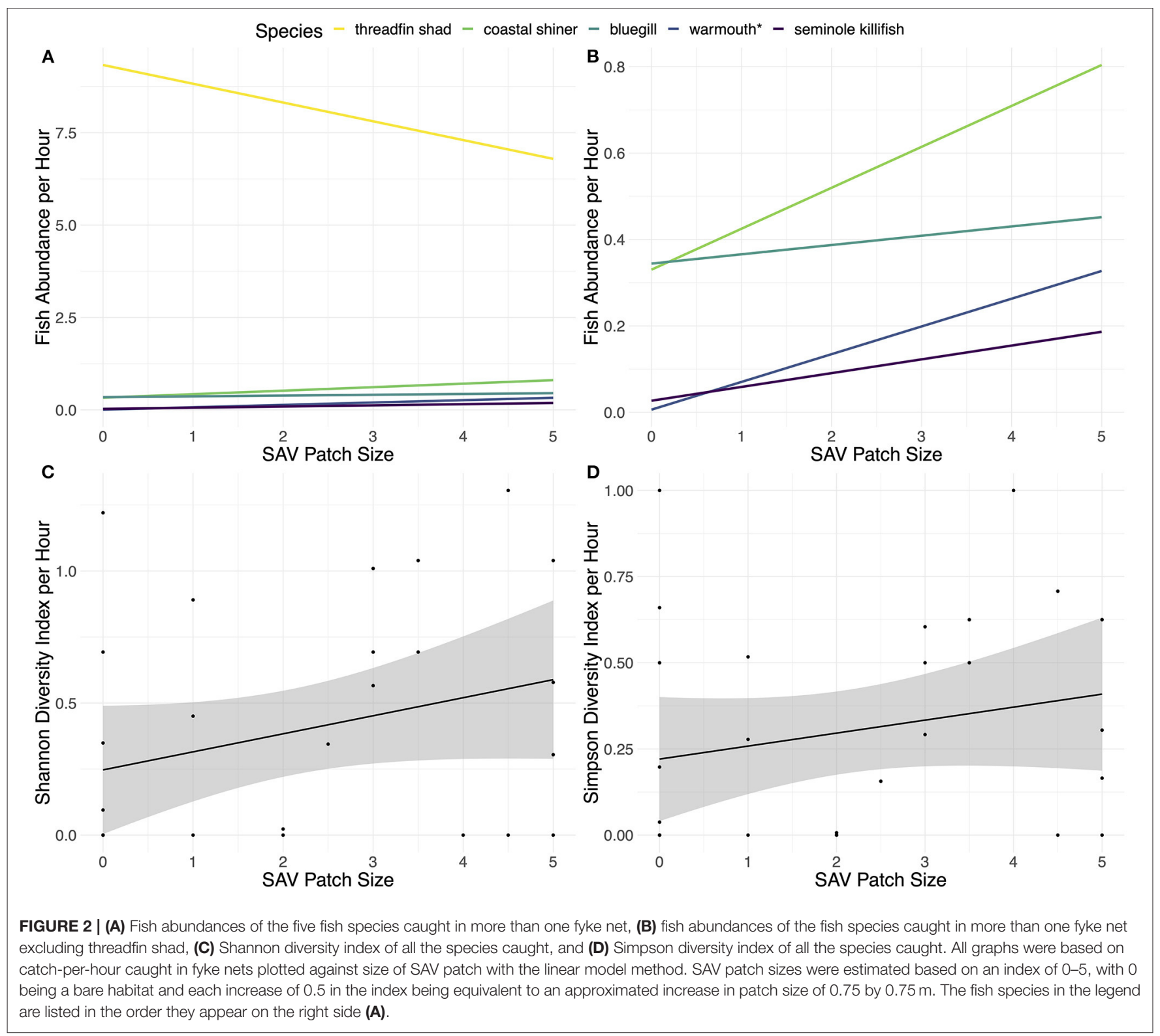

bowfin (Amia calva). A brown hoplo (Hoplosternum littorale) was also caught on one of the overnight trotlines. The brown hoplo is invasive and was the only fish caught in a bare habitat. All other species were caught in an SAV habitat (Table 2). Because of the low catch number, we lacked statistical power to perform any quantitative tests on the data. The number of worms eaten per hour, a measure of predation potential, was most affected by water temperature, wind speed, and time of day (multiple linear regression: adjusted $\mathrm{R}$-squared $=0.3043, F_{3,25}=5.082, p=0.007$, from anova function), but not any of the SAV-related variables.

\section{DISCUSSION}

SAV patch size was the most significant contributing environmental variable to fish community structure and total fish biomass. The abundance of threadfin shad, a pelagic schooling planktivore, decreased while all other species, many of them small and phytophilic, showed some increase with an increase in SAV patch size, as expected from their life-history traits (Bettoli et al., 1993). Total fish biomass increased more as a result of changing community composition than increasing abundance, as the community changed from being dominated by threadfin shad (average $1.0 \mathrm{~g}$ per individual among those sampled) to other species with strong associations to SAV for foraging and refugia, such as warmouth (average $56.6 \mathrm{~g}$ per individual among those sampled) and both juvenile and adult bluegill (average $5.4 \mathrm{~g}$ per individual among those sampled).

Compared to bare habitat or open water substrate, SAV usually increases abundance, biomass, and diversity of underwater communities (Lauridsen and Buenk, 1996; Thorp et al., 1997; Richardson et al., 1998). Intermediate to high 
TABLE 2 | All fishes caught on 2-h trotlines and overnight trotlines and the habitat type and SAV patch size in which they were captured.

\begin{tabular}{|c|c|c|c|}
\hline $\begin{array}{l}\text { Trotline } \\
\text { deployment }\end{array}$ & Habitat type & SAV patch size & Fish caught \\
\hline \multirow[t]{5}{*}{ 2-h trotlines $(n=29)$} & V. americana & 1 & $\begin{array}{l}1 \text { brown } \\
\text { bullhead, } 1 \\
\text { redear sunfish }\end{array}$ \\
\hline & V. americana & 4 & $\begin{array}{l}1 \text { brown } \\
\text { bullhead }\end{array}$ \\
\hline & P. illinoensis & 2.5 & 1 bowfin \\
\hline & P. illinoensis & 3.5 & $\begin{array}{l}1 \text { yellow } \\
\text { bullhead }\end{array}$ \\
\hline & $\operatorname{mix}$ & 3 & 1 bowfin \\
\hline $\begin{array}{l}\text { Overnight trotlines } \\
(n=6)\end{array}$ & bare & 0 & 1 brown hoplo \\
\hline
\end{tabular}

SAV patch sizes were estimated based on an index of 0-5, with 0 being a bare habitat and each increase of 0.5 in the index being equivalent to an approximated increase in patch size of 0.75 by $0.75 \mathrm{~m}$.

coverage of SAV also tends to lead to favorable community changes over low coverage of SAV (Beckett et al., 1992; Hargeby et al., 1994). An increase in SAV patch size would decrease the ratio of edge habitat to interior habitat. Aquatic communities may change between the exterior to the interior of SAV meadows possibly due to differences in predation, oxygen, or nutrients (Johnson and Hatch, 1991; Lauridsen and Buenk, 1996; Strayer et al., 2003; Fisher et al., 2012; Kauffman et al., 2018), and so changes in the quantity of edge habitat could lead to the documented differences in fish communities. The SAV patches sampled in Lake Apopka were the result of SAV restoration successes in a turbid-algal lake but were still relatively small compared to the SAV patch sizes expected in macrophytedominated lakes. As a result, it is possible the trends associated with increasing SAV patch size may be more parabolic than linear in nature.

SAV species assemblages, as represented by the habitat type and $H$. verticillata presence/absence environmental variables, did not have as large an impact as patch size in the results of our field sampling. SAV preferences can vary widely, even amongst similar functional groups. For example, Kondo and Abe (1995) demonstrated that one species of perch (Lates angustifrons) preferred Vallisneria sp. while the closely related $L$. mariae preferred Potamogeton schweinfurthii. Likewise, mosquitofish (Gambusia holbrooki), sailfin mollies (Poecilia latipinna), and dollar sunfish were all shown to prefer different SAV species (Chick and McIvor, 1997). Community assemblages of organisms like macroinvertebrates or free-floating zooplankton also occasionally do not vary at all between SAV species (Theel et al., 2008; Van Onsem et al., 2010; Cunha et al., 2011; Martin and Valentine, 2011). Effects of SAV species were not detected in our field sampling but can be important in determining habitat use of faunal communities.

Despite $H$. verticillata being the second most studied invasive aquatic macrophyte after Myriophyllum spicatum (Evangelista et al., 2014), the exact impacts of $H$. verticillata on fish communities remain equivocal. As an example, there have been mixed results of studies investigating $H$. verticillata's impacts on largemouth bass. A reduction in $H$. verticillata has been reported to improve growth, survival, reproduction, and recruitment, and to change predation and movement behavior of largemouth bass (Brown and Maceina, 2002; Allen et al., 2003; Sammons et al., 2003). In other studies, however, increased $H$. verticillata increased juvenile populations and year-class strength (Allen et al., 2003; Nagid et al., 2015) and reduced $H$. verticillata decreased recruitment, fishing effort, and catch of trophy-sized fish (Johnson et al., 2014). Still others showed no impact of $H$. verticillata on largemouth bass movement or catch rates (Maceina et al., 2008) or more widely on fish community measures (Hoyer et al., 2008). In our own field sampling, the presence or absence of $H$. verticillata did not significantly explain fish abundance, biomass, community composition, or predation potential. These variety of responses may be due in part to the negative impacts on fish $H$. verticillata can have at its highest densities, making it comparably beneficial to other SAV species only at lower, managed levels (Johnson et al., 2014).

The data from our field sampling did not have high predictive power due to several possible explanations. In the fyke nets, there was large variation in the catch of each sample, with one fyke net catch having 230 threadfin shad and three coastal shiners, far exceeding all other catches. Additionally, over half of the species caught in the fyke nets were only present in a single sample and the trotlines caught too few fish to analyze the data statistically. Lake Apopka has reportedly lower than expected abundance of largemouth bass (Murphy, 2005) and our method validation testing in Little Lake Conway suggests that Lake Apopka has overall lower or more disparate fish populations, which could explain the lower catches. Both sampling methods targeted more mobile species, and so may have excluded stationary species. Large predatory fish may occur in higher numbers in other habitats, such as emergent vegetation or woody debris (Sammons et al., 2003) and would therefore have been missed in our sampling. Both sampling methods used are also passive and may therefore not catch less abundant species due to low encounter rates. Much greater replication may have overcome these difficulties, which in our study was limited by suitable sites with adequate habitat availability. Our results were also limited to a single lake, so sampling more lakes would provide context for how widely they may be generalized. Despite the low predictive power, bias in species sampled, and limited spatial scope, the data collected were supported by the literature (Beckett et al., 1992; Hargeby et al., 1994; Lauridsen and Buenk, 1996; Thorp et al., 1997; Richardson et al., 1998) and still indicate a clear trend that SAV patch size is important in determining fish habitat use.

The results of our field sampling support the hypothesis that SAV restoration can increase fish habitat. In highly degraded lakes like Lake Apopka, adding any quantity of SAV is beneficial, but larger SAV patch size was more favorable, particularly for phytophilic fishes such as warmouth, bluegill, and other Centrarchids. There were no clear thresholds in upper and lower SAV patch sizes at least up to an approximated 7.5 by $7.5 \mathrm{~m}-$ the largest SAV patch sampled-though the literature suggests there may be detrimental effects to fish at higher SAV coverage 
and density (Beckett et al., 1992; Hargeby et al., 1994). Given the beneficial aspects of SAV patch size demonstrated in our study, when planning SAV restoration, focusing on areas that already have large patches of SAV that can be increased or replicated nearby may be more optimal than areas that have only produced small patches or less successful plantings. While SAV species assemblages can also impact fish habitat use, the species-specific preferences make it difficult to recommend one SAV species over another, and a more justified approach may be selection of SAV species based on the unique goals of each restoration.

\section{DATA AVAILABILITY STATEMENT}

The raw data supporting the conclusions of this article will be made available by the authors, without undue reservation.

\section{ETHICS STATEMENT}

The animal study was reviewed and approved by the Florida Fish and Wildife Conservation Commission for sampling under permit \#FNC-19-002 and by the University of Florida Institutional Animal Care and Use Committee under protocol \#202009978.

\section{AUTHOR CONTRIBUTIONS}

AL, LKR, CRA, and CWM conceptualized and designed the study and contributed to the revision of the manuscript. AL conducted

\section{REFERENCES}

Allen, M. S., Tugend, K. I., and Mann, M. J. (2003). Largemouth bass abundance and angler catch rates following a habitat enhancement project at Lake Kissimmee, Florida. N. Am. J. Fish. Manag. 23, 845-855. doi: 10.1577/M02-148

Bachmann, R. W., Hoyer, M. V., and Canfield, D. E. (2001). Evaluation of recent limnological changes at Lake Apopka. Hydrobiologia 448, 19-26. doi: 10.1023/A:1017564911355

Bachmann, R. W., Hoyer, M. V., and Canfield, D. E. Jr. (1999). The restoration of Lake Apopka in relation to alternative stable states. Hydrobiologia 394, 219-232. doi: 10.1023/A:1003638329772

Bachmann, R. W., Jones, B. L., Fox, D. D., Hoyer, M., Bull, L. A., and Canfield, D. E. Jr. (1996). Relations between trophic state indicators and fish in Florida (U.S.A.) lakes. Can. J. Fish. Aquat. Sci. 53, 842-855. doi: 10.1139/f95-236

Beckett, D. C., Aartila, T. P., and Miller, A. C. (1992). Invertebrate abundance on Potamogeton nodosus: effects of plant surface area and condition. Can. J. Zool. 70, 300-306. doi: 10.1139/z92-045

Bettoli, P. W., Maceina, M. J., Noble, R. L., and Betsill, R. K. (1993). Response of a reservoir fish community to aquatic vegetation removal. N. Am. J. Fish. Manag. 13, 110-124. doi: 10.1577/1548-8675(1993)013andlt;0110:ROARFCandgt;2.3.CO;2

Bonvechio, K. I., Sawyers, R. E., Bitz, R., and Crawford, S. (2014). Use of mini-fyke nets for sampling shallow-water fish communities in Florida lakes. N. Am. J. Fish. Manag. 34, 693-701. doi: 10.1080/02755947.2014. 901261

Brown, S. J., and Maceina, M. J. (2002). The influence of disparate levels of submersed aquatic vegetation on largemouth bass population characteristics in a Georgia reservoir. J. Aquat. Plant Manag. 40, 28-35. Available online at: https://www.apms.org/wp/wp-content/uploads/2012/10/v40p28.pdf the field sampling, performed the data analysis, prepared figures, and wrote the initial draft of the manuscript. All authors reviewed and agreed to the final manuscript.

\section{FUNDING}

Funding for this research and its publication was provided to LKR, CRA, and CWM by the St. Johns River Water Management District under Contract 31945.

\section{ACKNOWLEDGMENTS}

We thank St. Johns River Water Management District for funding and overseeing the project. Thank you to Micheal Allen, Stephen J. Walsh, and Jodi Slater for their inputs to planning and writing this research as well as Benjamin Baiser for assistance in determining appropriate statistical analyses. We also thank Scott Alford, Whitney Scheffel, Shea Husband, Anthony Messina, Alexandra Bijak, Caleb Hersey, and Natalia Medina for their field assistance. Thank you to reviewers for their constructive feedback on the manuscript.

\section{SUPPLEMENTARY MATERIAL}

The Supplementary Material for this article can be found online at: https://www.frontiersin.org/articles/10.3389/fcosc. 2021.657691/full\#supplementary-material

Carpenter, S. R., and Lodge, D. M. (1986). Effects of submersed macrophytes on ecosystem process. Aquat. Bot. 26, 341-370. doi: 10.1016/0304-3770(86)90031-8

Chick, J. H., and McIvor, C. C. (1997). Habitat selection by three littoral zone fishes: effects of predation pressure, plant density and macrophyte type. Ecol. Freshw. Fish. 6, 27-35. doi: 10.1111/j.1600-0633.1997.tb00139.x

Clugston, J. P. (1963). Lake Apopka, Florida, a changing lake and its vegetation. Q. J. Fla. Acad. Sci. 26, 168-174.

Cunha, E. R., Thomaz, S. M., Evangelista, H. B. A., Carniato, J., Souza, C. F., and Fugi, R. (2011). Small-sized fish assemblages do not differ between a native and a recently established non-indigenous macrophyte in a Neotropical ecosystem. Nat. Conserv. 9, 61-66. doi: 10.4322/natcon.2011.007

Diana, C. M., Jonas, J. L., Claramunt, R. M., Fitzsimons, J. D., and Marsden, J. E. (2006). A comparison of methods for sampling round goby in rocky littoral areas. N. Am. J. Fish. Manag. 26, 514-522. doi: 10.1577/M05-049.1

Dibble, E. D., Killgore, K. J., and Dick, G. O. (1996). Measurement of plant architecture in seven aquatic plants. J. Freshw. Ecol. 11, 311-318. doi: 10.1080/02705060.1996.9664453

Dibble, E. D., Killgore, K. J., and Harrel, S. L. (1997). Assessment of Fish-Plant Interactions. U.S. Army Corps of Engineers Miscellaneous Paper A-97-6. doi: 10.21236/ADA330052

Evangelista, H. B. A., Thomaz, S. M., and Umetsu, C. A. (2014). An analysis of publications on invasive macrophytes in aquatic ecosystems. Aquat. Invasions 9, 521-528. doi: 10.3391/ai.2014.9.4.10

Fisher, J. C., Kelso, W. E., and Rutherford, D. A. (2012). Macrophyte mediated predation on hydrilla-dwelling macroinvertebrates. Archiv. Hydrobiol. 181, 25-38. doi: 10.1127/1863-9135/2012/0174

Froese, R., and Pauly, D. (2019). FishBase: World Wide Web Electronic Publication Available online at: http://www.fishbase.org (accessed April 29, 2020). 
Hargeby, A., Andersson, G., Blindow, I., and Johansson, S. (1994). Trophic web structure in a shallow eutrophic lake during a dominance shift from phytoplankton to submerged macrophytes. Hydrobiologia 279, 83-90. doi: $10.1007 / \mathrm{BF} 00027843$

Harrel, S. L., and Dibble, E. D. (2001). Factors affecting foraging patterns of juvenile bluegill (Lepomis macrochirus) in vegetated habitats of a Wisconsin lake. J. Freshw. Ecol. 16, 581-589. doi: 10.1080/02705060.2001.9663850

Hoyer, M. V., Jackson, M. W., Allen, M. S., and Canfield, D. E. Jr. (2008). Lack of exotic hydrilla infestation effects on plant, fish and aquatic bird community measures. Lake Reserv. Manag. 24, 331-338. doi: 10.1080/07438140809354843

Hubert, W. A., Pope, K. L., and Dettmers, J. M. (2012). "Passive capture techniques," in Fisheries Techniques, $3 r d$ Ed., eds A. V. Zale, D. L. Parrish, and T. M. Sutton (Bethesda, MD: American Fisheries Society), 223-265.

Johnson, J. D., and Hatch, J. T. (1991). Life-history of the least darter Etheostoma microperca at the northwestern limits of its range. Am. Midl. Nat. 125, 87-103. doi: $10.2307 / 2426372$

Johnson, K. G., Dotson, J. R., Pouder, W. F., Trippel, N. A., and Eisenhauer, R. L. (2014). Effects of hurricane-induced hydrilla reduction on the largemouth bass fishery at two central Florida lakes. Lake Reserv. Manag. 30, 217-225. doi: 10.1080/10402381.2014.908254

Kauffman, T. C., Martin, C. W., and Valentine, J. F. (2018). Hydrological alteration exacerbates the negative impacts of invasive Eurasian milfoil Myriophyllum spicatum by creating hypoxic conditions in a northern Gulf of Mexico estuary. Mar. Ecol. Prog. Ser. 592, 97-108. doi: 10.3354/meps 12517

Killgore, K. J., Dibble, E. D., and Hoover, J. J. (1993). Relationships Between Fish and Aquatic Plants: A Plan of Study. U.S. Army Corps of Engineers Miscellaneous Paper A-93-A-91.

Kondo, T., and Abe, N. (1995). Habitat preference, food habits and growth of juveniles of Lates angustifrons and Lates mariae (Pisces, Centropomidae) in Lake Tanganyika. Ecol. Res. 10, 275-280. doi: 10.1007/BF02347853

Lauridsen, T. L., and Buenk, I. (1996). Diel changes in the horizontal distribution of zooplankton in the littoral zone of two shallow eutrophic lakes. Archiv. Hydrobiol. 137, 161-176.

Legendre, P., and Gallagher, E. D. (2001). Ecologically meaningful transformations for ordination of species data. Oecologia 129, 271-280. doi: $10.1007 /$ s004420100716

Maceina, M. J., Marshall, M. D., and Sammons, S. M. (2008). Impacts of endothall applications on largemouth bass spawning behavior and reproductive success. N. Am. J. Fish. Manag. 28, 1812-1817. doi: 10.1577/M08-041.1

Martin, C. W., and Valentine, J. F. (2011). Impacts of a habitat-forming exotic species on estuarine structure and function: an experimental assessment of Eurasian milfoil. Estuar. Coast. 34, 364-372. doi: 10.1007/s12237-0109274-5

Martin, C. W., and Valentine, J. F. (2012). Eurasian milfoil invasion in estuaries: physical disturbance can reduce the proliferation of an aquatic nuisance species. Mar. Ecol. Prog. Ser. 449, 109-119. doi: 10.3354/meps09515

Murphy, S. J. (2005). Assessment of fish and plant communities in Lake Apopka, FL (Master's thesis). Gainesville, FL: University of Florida.

Nagid, E. J., Tuten, T., and Johnson, K. G. (2015). Effects of reservoir drawdowns and the expansion of hydrilla coverage on year-class strength of largemouth bass. N. Am. J. Fish. Manag. 35, 54-61. doi: 10.1080/02755947.2014.963750

Oksanen, J., Blanchet, F. G., Friendly, M., Kindt, R., Legendre, P., McGlinn, D., et al. (2019). Vegan: Community Ecology Package. R package version 2.5-6.

Pine, W. E. I. I. I., Martell, S. J. D., Walters, C. J., and Kitchell, J. F. (2009). Counterintuitive responses of fish populations to management actions. Fisheries 34, 165-180. doi: 10.1577/1548-8446-34.4.165
Puntila, R. I., Martin, C. W., and Valentine, J. F. (2012). Measuring predation with a new design of submersible chronographic timer. Bull. Mar. Sci. 88, 1115-1122. doi: $10.5343 / \mathrm{bms}, .2012 .1011$

R Core Team (2019). R: A Language and Environment for Statistical computing. R Core Team.

Richardson, W. B., Zigler, S. J., and Dewey, M. R. (1998). Bioenergetic relations in submerged aquatic vegetation: an experimental test of prey use by juvenile bluegills. Ecol. Freshw. Fish 7, 1-12. doi: 10.1111/j.1600-0633.1998. tb00167.x

Sammons, S. M., Maceina, M. J., and Partridge, D. G. (2003). Changes in behavior, movement, and home ranges of largemouth bass following large-scale hydrilla removal in Lake Seminole, Georgia. J. Aquat. Plant Manag. 41, 31-38. Available online at: http://www.apms.org/japm/vol41/v41p31.pdf

Short, F. T., Kosten, S., Morgan, P. A., Malone, S., and Moore, G. E. (2016). Impacts of climate change on submerged and emergent wetland plants. Aquat. Bot. 135, 3-17. doi: 10.1016/j.aquabot.2016. 06.006

Slagle, Z. J., and Allen, M. S. (2018). Should we plant macrophytes? Restored habitat use by the fish community of Lake Apopka, Florida. Lake Reserv. Manag. 34, 296-305. doi: 10.1080/10402381.2018.1443179

Strayer, D. L., Lutz, C., Malcom, H. M., Munger, K., and Shaw, W. H. (2003). Invertebrate communities associated with a native (Vallisneria americana) and an alien (Trapa natans) macrophyte in a large river. Freshw. Biol. 48, 1938-1949. doi: 10.1046/j.1365-2427.2003.01142.x

Theel, H. J., Dibble, E. D., and Madsen, J. D. (2008). Differential influence of a monotypic and diverse native aquatic plant bed on a macroinvertebrate assemblage; an experimental implication of exotic plant induced habitat. Hydrobiologia 600, 77-87. doi: 10.1007/s10750-007-9177-z

Thorp, A. G., Jones, R. C., and Kelso, D. P. (1997). A comparison of watercolumn macroinvertebrate communities in beds of differing submersed aquatic vegetation in the tidal freshwater Potomac River. Estuaries 20:86. doi,: $10.2307 / 1352722$

US Environmental Agency (1978). Lake Apopka restoration project Lake and Orange Counties Florida. US Environmental Agency.

Van Onsem, S., De Backer, S., and Triest, L. (2010). Microhabitat-zooplankton relationship in extensive macrophyte vegetations of eutrophic clear-water ponds. Hydrobiologia 656, 67-81. doi: 10.1007/s10750-010-0442-1

Wickham, H. (2007). Reshaping data with the reshape package. J. Stat. Softw. 21, 1-20. doi: 10.18637/jss.v021.i12

Wickham, H. (2016). ggplot2: Elegant Graphics for Data Analysis. doi: 10.1007/978-3-319-24277-4

Zhang, Y., Jeppesen, E., Liu, X., Qin, B., Shi, K., Zhou, Y., et al. (2017). Global loss of aquatic vegetation in lakes. Earth Sci. Rev. 173, 259-265. doi: 10.1016/j.earscirev.2017.08.013

Conflict of Interest: The authors declare that the research was conducted in the absence of any commercial or financial relationships that could be construed as a potential conflict of interest.

Copyright (c) 2021 Looby, Reynolds, Adams and Martin. This is an open-access article distributed under the terms of the Creative Commons Attribution License (CC BY). The use, distribution or reproduction in other forums is permitted, provided the original author(s) and the copyright owner(s) are credited and that the original publication in this journal is cited, in accordance with accepted academic practice. No use, distribution or reproduction is permitted which does not comply with these terms. 